\title{
POLÍTICAS PÚBLICAS PARA O USO DAS NOVAS TECNOLOGIAS NA EDUCAÇÃO: EN- TREO REAL E O IDEAL DE QUALIDADE
}

\author{
Stela Galbardi de Resende ${ }^{1}$; Roseli Gall do Amaral da Silva². \\ ${ }^{1}$ Faculdade Astorga - FAAST, Astorga, PR. ${ }^{2}$ Universidade Tecnológica Federal Do Paraná - UTFPR, Apucarana, PR. E- \\ mail: stela.galbardi@gmail.com
}

\begin{abstract}
RESUMO
Este trabalho tem como objetivo refletir sobre as Políticas Públicas para o uso das novas tecnologias da informação e comunicação na educação, em como o Estado brasileiro se articula em ações intencionais mais nem sempre explícitas para o atingimento de uma suposta qualidade do ensino e da redução das desigualdades educacionais. Melhorar a qualidade educacional é uma das metas perseguidas pelo Brasil nas últimas décadas, entretanto esse processo é antagônico na medida em que se estabelece uma discussão dialética dos conceitos de Sociedade, Estado, Políticas Públicas e seus reflexos no ideal de qualidade proposto pelo capital. A meta é discutir algumas questões inerentes a inserção das tecnologias no contexto educacional, sem, contudo, comprometer a qualidade do ensino, e assim aumentar a desigualdade e a exclusão.
\end{abstract}

Palavras-chave: Políticas Públicas, Qualidade Educacional, Ideologia, NTICs.

\section{PUBLIC POLICIES FOR THE USE OF NEW TECHNOLOGIES IN EDUCATION: REAL INTERIOR AND THE IDEAL QUALITY}

\begin{abstract}
This work aims to reflect on the Public Policies for the use of new information and communication technologies in education, in how the Brazilian State articulates itself in intentional actions that are not always explicit for the achievement of a supposed quality of education and the reduction of educational inequalities. Improving educational quality is one of the goals pursued by Brazil in the last decades. However, this process is antagonistic in that it establishes a dialectical discussion of the concepts of Society, State, Public Policies and its reflections on the ideal of quality proposed by capital. The goal is to discuss some issues inherent in the insertion of technologies in the educational context, without, however, compromising the quality of education, and thus increasing inequality and exclusion.
\end{abstract}

Keywords: Public Policies, Educational Quality, Ideology, New Technologies of Information and Education. 


\section{INTRODUÇÃO}

Para discutir políticas públicas para a educação implica considerar que as mesmas articulam-se ao projeto de sociedade que se pretende implantar ou que está em curso. Admitindo que o conceito de sociedade vai além do coletivo de cidadãos de um país, pode-se compreendê-la como um conjunto de relações estabelecidas entre os homens para produzir as condições de subsistência, que por sua vez implica em transformações tanto da natureza como de si mesmos, como por exemplo a divisão social resultante da relação capital $x$ trabalho. Essas relações sociais definem tanto a forma de atuação, como o papel do Estado nesta sociedade. O Estado pode ser definido como um contrato social e legal formado por uma organização burocrática e um sistema jurídico formal, é uma estrutura política que se sobrepõe a sociedade ao mesmo tempo em que faz parte dela. É a sociedade e suas relações que dão forma jurídica e política estatal que por sua vez regula, acompanha e avalia esta sociedade por meio da lei, da força e do aparelho ideológico, onde se encontra também a educação.

\section{METODOLOGIA}

Para a construção da pesquisa utilizou-se um levantamento bibliográfico e documental com abordagem qualitativa. A pesquisa bibliográfica realizada permitiu melhor situar o tema e as reflexões teóricas que problematizam e compreendem as implicações teorico-práticas na formação docente.

\section{RESULTADOS}

A cada modelo de Estado também corresponde uma proposta de educação, uma vez que "todo projeto educativo, todo discurso educativo veicula uma imagem de homem, uma visão de homem" (GADOTTI, 1984, p. 144) que se deseja formar. Dito de outra forma, a política educacional defendida por um determinado governo reflete como ele entende o mundo e as relações que se estabelecem na sociedade.

Em uma sociedade capitalista as relações são pautadas na desigualdade e na divisão de classes desde a sua concepção. Na divisão social resultante da relação capital $x$ trabalho juntamente com as contradições de uma produção coletiva e apropriação privada. O Estado não está acima dos conflitos e contradições dessa sociedade, pelo contrário, é produto dessas relações contraditórias. Portanto suas políticas, por sua vez também são contraditórias.

Sobre isso Mascaro afirma:

O Estado é um derivado necessário da própria reprodução capitalista; essas relações ensejam sua constituição ou sua formação. Sendo estranho a cada burguês e a cada trabalhador explorado, individualmente tomados, é, ao mesmo tempo, elemento necessário de sua constituição e da reprodução de suas relações sociais. (MASCARO, 2013, p.19)

Sendo assim, a sociedade sendo um sistema de relação que se estabelece, na sociedade capitalista a relação é com o lucro, que advém do excedente de produção que é apropriado, na concentração de riqueza e centralização do capital ao mesmo tempo em que produz a reserva de trabalho. Partindo do princípio que o sistema político-econômico atual tem seus fundamentos no neoliberalismo, que predispõe ações de redução gradativa na intervenção do Estado na economia e na sociedade e reduz o indivíduo a mero consumidor priorizando não mais a liberdade do indivíduo e sim a liberdade econômica das grandes organizações, cabe discutir qual a sua influência nas Políticas Educacionais.

O Governo pode ser entendido como um conjunto de programas e projetos que parte da sociedade. Sendo o Governo o Estado em ação usando a estrutura do Estado, então a Política é o campo de ação e de estudo do Estado que tem o poder de atuar, proibir, regular, ordenar, planejar, legislar, intervir e organizar a vida social no intuito de guardar e defender os interesses das classes (capital $x$ trabalho) e desta relação e de sua continuidade. A especificidade histórica do 
Estado capitalista tem sua relação estrutural contraditória, conflituosa, instável e muitas vezes opostas. A autonomia estatal (ente terceiro) deve velar por esta relação, a disputa se encontra é na apropriação do excedente.

Como afirma David Harvey:

O neoliberalismo é em primeiro lugar uma teoria das práticas político-econômicas que propõe que o bem-estar humano pode ser melhor promovido liberando-se as liberdades e capacidades empreendedoras individuais no âmbito de uma estrutura institucional apropriada a essas práticas: o Estado tem de garantir, por exemplo, a qualidade e a integridade do dinheiro. (HARVEY, 2011, p.12)

Para isso o neoliberalismo propõe o modelo educacional baseado no trabalho alienado que está ligado à divisão entre a superestrutura - produto da classe dominante - detentores da cultura, bastidores dos fatos ou ainda autores; e a base - classe dominada - atores das decisões da classe dominante, ou seja, a educação pretendida insere-se no modelo de homem pretendido pelo capitalismo. Como prevê, o art 1ㅇ § 2어 da LDB n 9394/96 o direcionamento da educação escolar primeiramente para o mundo do trabalho, e não somente enfatizando uma educação unilateral, técnica e reprodutiva.

Como afirma David Harvey:

os defensores da proposta neoliberal ocupam atualmente posições de considerável influência no campo da educação (nas universidades e em muitos "bancos de idéias), nos meios de comunicação, em conselhos de administração de corporações e instituições financeiras, em instituições-chave do Estado (áreas do Tesouro, bancos centrais), bem como em instituições internacionais como o Fundo Monetário Internacional (FMI), o Banco Mundial e a Organização Mundial do Comércio (OMC), que regulam as finanças e o comércio globais. Em suma, o neoliberalismo se tornou hegemônico como modalidade de discurso e passou a afetar tão amplamente os modos de pensamento que se incorporou às maneiras cotidianas de muitas pessoas interpretarem, viverem e compreenderem o mundo. (HARVEY, 2011, p.13)

Partindo do pressuposto de que a política fundamenta-se em ideias que podem se efetivar, ou não se efetivar em programas e ações do Estado (Ideologia), sabendo que o Estado nunca é neutro, e que toda ideia refere-se a disputa de poder e interesses da luta de classes, o processo cíclico de construção da política, mesmo parecendo ser explícito abarca razões subjacentes.

Nesse sentido, esse trabalho de pesquisa tem como objetivo refletir sobre as Políticas Públicas para o uso das novas tecnologias da informação e comunicação ${ }^{1}$ na educação, em como o Estado brasileiro se articula em ações intencionais mais nem sempre explícitas para o atingimento de uma suposta qualidade do ensino e da redução das desigualdades educacionais. $O$ discurso de qualidade educacional, nesse contexto, é legítimo, mas é legítimo questionar a intenção de um Estado que se articula de forma diferente ao seu discurso, ou seja, se não é de forma igualitária que a tecnologia e profissionais qualificados para seu uso acontece, a desigualdade permanece e perpetua.

A sociedade interligada por redes de tecnologia digital é resultado do desenvolvimento de softwares, hardwares e tecnologias que atendem à expansão do mercado mundial. Em meio a esse processo, a educação passou por mudanças que vêm ao encontro dessa realidade. (ALVES; NOVA, 2003 apud COSTA; LOZANO, 2013).

A Educação a Distância é a modalidade de educação efetivada por meio do intenso uso dessas tecnologias de informação e comunicação. A EaD é uma modalidade educacional que usa como artifício as TICs, que se transformam em materiais (recursos) didáticos, desde que aplicadas intencionalmente ao processo educativo, promovendo a construção e a socialização do conheci-

\footnotetext{
${ }^{1}$ Ao tratar o termo novas tecnologias, entende-se como "novas" as disponíveis na última década.
} 
mento (BOLSONI, 2015). Nessa modalidade, Ensino Superior pode chegar a lugares nos quais o acesso presencial é difícil, o que em tese democratiza e interioriza a oferta desse nível de ensino superior no Brasil (COSTA; LOZANO, 2013). A EaD possibilita além da democratização do conhecimento, uma oportunidade ímpar para a formação continuada e uma melhor qualificação profissional, inclusive no que diz respeito a utilização de suas ferramentas.

A partir disto é possível refletir que a legislação aponta para a necessidade de uma formação do profissional de ensino e capacitação para a utilização das TICs como recurso pedagógico em sala de aula, o que efetivamente não acontece. No contexto da utilização das tecnologias de informação e comunicação (TICS) na escola, evidenciam-se desafios e problemas relacionados aos espaços e aos tempos que o uso das tecnologias novas e convencionais provocam nas práticas pedagógicas que ocorrem no cotidiano da escola. Para entendê-los e superá-los é fundamental analisar como tem sido a formação profissional e as potencialidades das tecnologias disponíveis e a realidade em que a escola se encontra inserida, identificando as características do trabalho pedagógico que nela se realiza, de seu corpo docente e discente, de sua comunidade interna e externa. E qual colaboração a EaD pode oferecer a fim de proporcionar espaços para esta formação.

Para Papert (2001), a configuração tradicional dos currículos deve ser revista para incorporar necessidades da era da informação, já que a atual organização dos currículos pertence a uma era pré-digital, possivelmente os currículos deverão ser revistos e acrescentados os sistemas nos quais o conhecimento pode ser obtido quando e onde for necessário.

Ainda, segundo Altoé; Costa e Teruya (2005), o objeto de preocupação no que diz respeito a educação e o uso de novas tecnologias está vinculado a prática docente, a uma formação que inclua a utilização dos recursos midiáticos de forma eficaz. Pois o que pode determinar a qualidade da mediação pedagógica é a formação do professor - domínio técnico pedagógico, a concepção de educação, a estratégia de ensino e o enfoque educacional, que deve estar adequado à proposta curricular.

\section{DISCUSSÃO}

No contexto da utilização de tecnologias na educação, como recursos importantes, não somente pelas informações que disponibilizam, mas pelo processo comunicacional e interacional que possibilitam, conduzindo a (re) construção de conhecimentos. Trata-se de utilizar das tecnologias como fatores de formação de consciência que, podem expandir os espaços de aprendizagem, ampliando as possibilidades de construção e consolidação desse processo.

Para Lenoir apud Vosgerau "o planejamento das situações de ensino-aprendizagem é base para a transformação das tecnologias em recursos educativos". Planejamento requer intenção, sistematização, objetivos definidos "do que se quer ensinar, para quem, com que recursos e como ensinar" (LENOIR apud VOSGERAU, 2010, p.3). Assim, o papel do professor assume grande importância na instrumentalização das tecnologias em ambientes de aprendizagem:

A partir dessas premissas, o professor é o mediador didático-pedagógico dos processos de ensino e de aprendizagem fazendo uso das tecnologias de informação e comunicação de modo que perpassem o planejamento de ensino como recursos que potencializam a aprendizagem dos educandos e enriqueçam a prática do professor (PARANÁ, 2010, p. 13).

A justificativa para incorporar as novas tecnologias às práticas educativas foi explicada em numerosas obras e estudos nacionais e internacionais. Entre as justificativas cabe destacar: a adequação do sistema escolar às características da sociedade da informação; preparação de crianças e jovens para as novas formas culturais digitais; incremento e melhoria da qualidade dos processos de ensino; inovação dos métodos e materiais didáticos, entre outras. (PIMENTEL, 2012)

Para atender as especificações dos referenciais legais, na tentativa de minimizar a distância entre tecnologia e efetiva utilização no contexto educacional público, faz-se necessário a formação 
docente no sentido de dar suporte para a efetiva utilização dessas tecnologias de forma a incluí-las na práxis pedagógica visando uma maior qualidade de ensino.

E sobre a necessidade de habilitar os professores para esse exercício:

Para aproveitar as vantagens das tecnologias móveis, os professores precisam ser treinados para incorporá-las com sucesso na prática pedagógica. Em muitos casos, o investimento do governo na formação de professores é mais importante do que seu investimento em tecnologia em si. A pesquisa da UNESCO mostrou que, sem orientação e instrução professores, muitas vezes, usam a tecnologia para "fazer as coisas velhas em novas formas", em vez de transformar e melhorar métodos de ensino e aprendizagem (UNESCO, 2013, p. 31). ${ }^{2}$

Conforme Libâneo: “A mediação do professor consiste em problematizar, perguntar, dialogar, ouvir os alunos, ensiná-los a argumentar, abrir-lhes espaço para expressar seus pensamentos, sentimentos, desejos, de modo que tragam para a aula sua realidade vivida" (LIBÂNEO, 2009, p. 13). Os professores então são os mediadores capazes de transformar as ferramentas de tecnologia em instrumentos de ensino-aprendizagem, dando-Ihes vida conforme o contexto e a realidade da disciplina e da sala de aula.

A adoção de novas tecnologias no ensino não tem um objetivo em si mesma, mas é um recurso no processo de ensinar e aprender para alcançar os fins educacionais almejados, dentre os quais ampliação da oferta e qualidade. Vivemos uma época de grandes transformações. O desenvolvimento científico gera, entre outros produtos, um enorme avanço na tecnologia e no conhecimento.

Numa sociedade digital e em permanente transformação, o professor deve estar preparado para capacitar seus alunos a desenvolverem competências para resolver situações complexas e inesperadas e necessita, também, encarar a si mesmo e a seus alunos como uma equipe de trabaIho com desafios novos e diferenciados a vencer e com responsabilidades individuais e coletivas a cumprir. Numa sociedade extremamente desigual e heterogênea como a brasileira, a formação docente transita por uma crise.

Essa crise em suas bases, é uma questão de âmbito mundial como afirma Nóvoa (2009). Em síntese:

Para Nóvoa deve assumir um forte componente prático, centrado na aprendizagem dos alunos e no estudo de casos concretos. Assumir uma postura reflexiva a respeito da profissão, isto é, basear-se na aquisição de uma cultura profissional, valorizando experiências práticas como papel central na formação docente. Dedicar uma atenção especial às dimensões pessoais, trabalhando a capacidade de relação e de comunicação que define o trato pedagógico; valorizar o trabalho em equipe e o exercício coletivo da profissão; e, por fim, a formação deve estar marcada por um princípio de responsabilidade social, favorecendo a comunicação pública e a participação dos professores em espaços públicos da educação (AMARAL, R.G. et al, 2015, p.11).

Nesse sentido, a reflexão sobre a prática assume função essencial como formadora e, não a prática isolada em si mesma (NÓVOA, 2007), não é a prática que é formadora, mas sim a reflexão sobre a prática. É a capacidade de refletir e analisar a própria prática na interação com todos os participantes do processo formador que provoca e renova a práxis pedagógica.

Os desafios colocados pelas novas tecnologias têm revolucionado o dia-a-dia das sociedades e das escolas. Mas, como bem escreve Manuel Castells, o essencial reside na aquisição de uma capacidade intelectual de aprendizagem e de desenvolvimento, o que coloca os professores no

\footnotetext{
${ }^{2}$ To capitalize on the advantages of mobile technologies, teachers need to be trained to successfully incorporate them into pedagogical practice. In many instances, a government's investment in teacher training is more important than its investment in technology itself. UNESCO's research has shown that without guidance and instruction teachers will often use technology to 'do old things in new ways' rather than transform and improve approaches to teaching and learning (UNESCO, 2013, p. 31).
} 
centro de uma "nova pedagogia" (CASTELLS apud NÓVOA, 2009, p. 13). E exige deles uma nova postura crítico-reflexiva sobre sua própria prática. E em especial sobre as políticas públicas. Faz-se necessário analisá-las como expressão das ideias da classe dominante e, portanto, como antagônicas já que expressam o interesse do capital que se alimenta das desigualdades. Nesse sentido, 0 ciclo de políticas, no que diz respeito a qualidade, em um contexto de influências (ideias) voltadas para o uso das novas tecnologias na educação almejando um padrão de qualidade que visa a redução das desigualdades, em um discurso político-ideológico só poderá ser efetivado em uma formação omnilateral.

\section{CONCLUSÃO}

O homem omnilateral pode ser conceituado como um homem consciente dos problemas do seu tempo, do seu mundo, capaz de realizar operações críticas e criativas de análise e de síntese que possibilitem ao indivíduo, mediante uma visão totalizante dos fatos isolados, compreender a sociedade, intervir, e tomar decisões coerentes com um projeto que visa à humanização e a emancipação social.

A formação da consciência crítica, portanto, perpassa a capacidade de pensar a ação em suas continuidades e mudanças do tempo. Neste contexto, as Novas Tecnologias necessitam ser discutidas, a partir das possibilidades que o ciberespaço oferece para a criação de novos padrões de aquisição e construção dos conhecimentos, ao permitir o uso integrado e interativo de diversas mídias, a exploração hipertextual de um volume enorme de informações e a comunicação a distância.

Mas, faz-se necessário na formação de um modelo de homem omnilateral, além do conhecimento técnico, também uma formação filosófica e política no sentido de capacitá-lo a tornar-se não somente ator, mas também autor, capaz de fazer uma leitura e interpretação do contexto histórico e não somente reproduzi-lo. Capaz de compreender as ações intencionais e implícitas do Estado por meio das políticas públicas e não se conformar com políticas sociais ideológicas e contraditórias. Capaz de analisar criticamente a realidade e transformá-la, desvendando que o principal desafio das classes subalternas é encontrar formas organizativas que permitam barrar o processo de exclusão política e social desencadeado pelas propostas do Governo que efetivem a qualidade na educação.

\section{REFERÊNCIAS}

AMARAL, R.G. Roseli Gall; et al. O pedagógico entra em cena na universidade tecnológica: experiências em ensino, pesquisa e extensão na UTFPR campus Apucarana. Apucarana, Ed. Platão, 2015.

BOLSONI, Evandro Paulo (Org.). O Sucesso da EAD Pelo olhar de quem faz. Maringá-PR: Linkania, 2015. p. 97.

BRASIL. DE DIRETRIZES, Lei; DA EDUCAÇÃO, Bases. LEI n 9.394, de 20 de Dezembro de 1996. Estabelece as diretrizes e bases da educação nacional. Brasília (Brasil).

COSTA, Maria Luísa Furlan; ALTOÉ, Anair (Org.); TERUYA, Tereza Kazuko (Org.). Educação e Novas Tecnologias. 1. ed. Maringá: Eduem, 2005.

COSTA, Maria Luisa Furlan; LOZANO, Taissa Vieira . Educação a Distância e Deficiência Visual: Possibilidades e Perspectivas. 2013.2 Disponível em: <http://proxy.furb.br/ojs/index.php/atosdepesquisa/article/viewFile/3431/2482> Acesso em 16 de junho 2018.

GADOTTI, Moacir. A educação contra a educação. Rio de Janeiro: Paz e Terra, 1984 
HARVEY, David. O Neoliberalismo: história e implicações. 2ª ed., São Paulo, Edições Loyola, 2011.

LIBÂNEO, J. C. Adeus professor, adeus professora? Novas exigências educacionais e profissão docente. 9. ed. São Paulo: Cortez, 2009. p. 10-20. v. 67. (Questões de nossa época)

MASCARO, Alysson L. Estado e forma política. São Paulo, Boitempo, 2013.

NÓVOA, António. Professores: Imagens do futuro Presentes. Lisboa. Educa, 2009.

Desafios do professor no mundo contemporâneo. Livreto publicado pelo Sindicato dos

Professores de São Paulo, 2007. Disponível in <http://www.sinprosp.org.br/arquivos/novoa/livreto novoa.pdf > Acesso em 16 de junho 2018. PAPERT, S. A maior vantagem competitiva é a habilidade de aprender in Super Interessante Especial - Educação Digital, Abril de 2001.

PARANÁ. Diretrizes para o uso de tecnologias educacionais / Secretaria de Estado da Educação. Superintendência da Educação. Diretoria de Tecnologias Educacionais. - Curitiba: SEED - Pr., 2010. - p. - (Cadernos temáticos).

PIMENTEL, Maria Nada. As políticas públicas para as tecnologias de informação e comunicação e educação a distância no Brasil. Educ. foco, Juiz de Fora, v. 17, n. 2, p. 83-102 jul. / out. 2012. Disponível em <http://www.ufjf.br/revistaedufoco/files/2013/05/artigo4.pdf > acesso em 17 de junho 2018.

UNESCO, Diretrizes de Políticas para a Aprendizagem Móvel. 2013. Disponível em: $<$ www.unesco.org/open-access/terms-use-ccbyncnd-port>. Acesso em 16 de junho 2018.

VOSGERAU, D. Orientações para a integração dos recursos tecnológicos à proposta de trabalho do professor. Texto impresso, 2010. 